\title{
Extensive Calcinosis Cutis in Limited Cutaneous Scleroderma
}

RENÉ THONHOFER, MD; CORNELIA SIEGEL, MD, Department of Internal Medicine, State Hospital Muerzzuschlag, 63-65 Grazer Strasse, A-8680 Muerzzuschlag, Austria. Address correspondence to Dr. Thonhofer; E-mail: rene_thonhofer@hotmail.com. J Rheumatol 2009;36:2834-5; doi:10.3899/jrheum.090633

The CREST syndrome is a subset of limited scleroderma characterized by calcinosis cutis, Raynaud's phenomenon (RP), esophageal dysmotility, sclerodactyly, and telangiectasias. The calcinosis of skin and soft tissues results from deposition of calcium hydroxyapatite crystals and occurs to a different extent in $20 \%-40 \%$ of patients. The exact mechanism of calcinosis associated with scleroderma is not known and no effective drug therapy exists, therefore the therapeutic approach is mostly symptom-oriented. Sometimes a surgical intervention, especially in paraspinal calcifications, may be necessary.

A 71-year-old woman presented with calcinosis cutis, Raynaud's phenomenon, esophageal dysmotility, sclerodactyly, and facial telangiectasias 20 years ago. She was diagnosed with CREST syndrome, now classified as lim- ited cutaneous scleroderma $(\mathrm{lcSSc})^{1,2}$. Antinuclear antibodies and anticentromere antibodies were positive ${ }^{3}$. She had never received specific therapy, and concomitant arthralgias occasionally were treated with nonsteroidal antiinflammatory drugs. Physical examination revealed marked skin thickening of hands, forearms, feet, and the face, as well as multiple indurated, confluent, yellowish nodules on hands and forearms bilaterally. Radiographs of hands (Figure 1) and forearms (Figure 2) showed extensive confluent calcifications typically seen in $1 \mathrm{cSSc}$. Followup visits in our outpatient clinic during the last 2 years revealed a stable extent of calcification and skin thickening, but increasing complications caused by esophageal dysmotility.

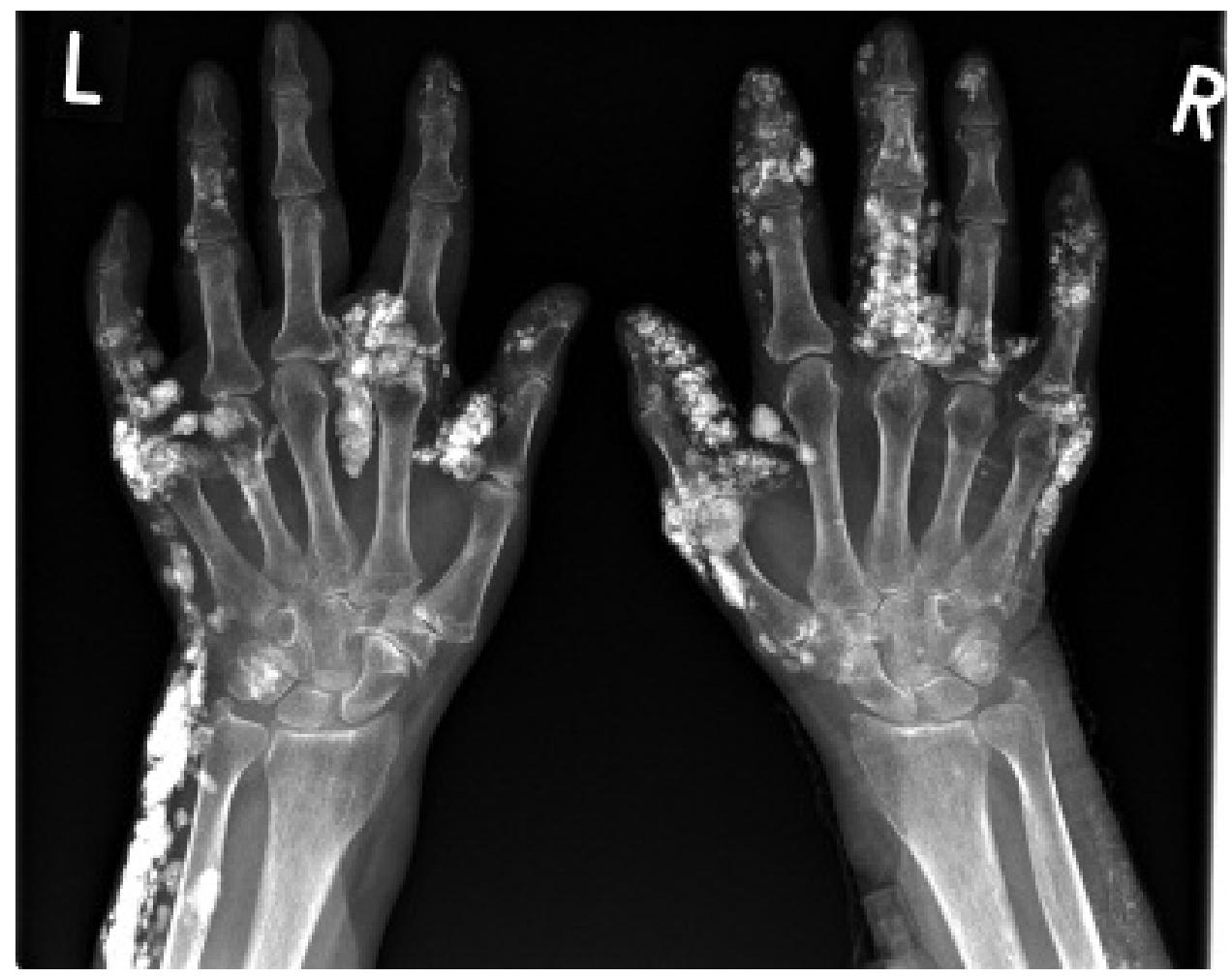

Figure 1. Radiograph of hands shows extensive confluent calcifications typically seen in lcSSc. 


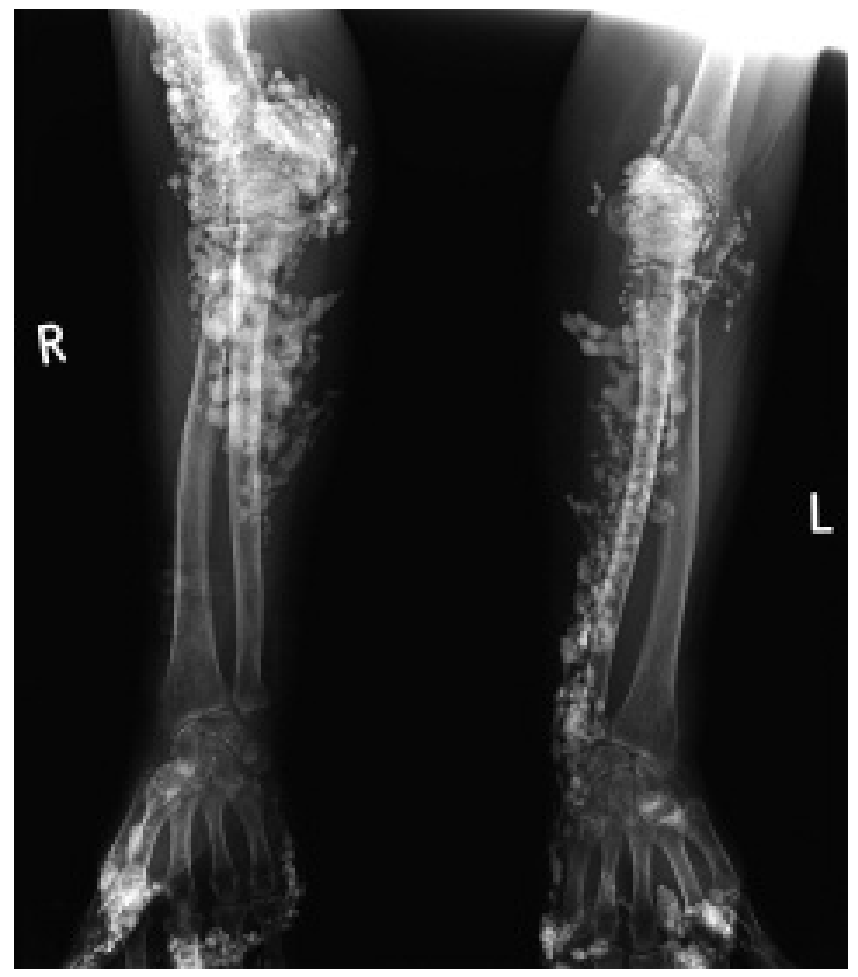

Figure 2. Radiograph of forearms also shows extensive calcifications.

\section{REFERENCES}

1. LeRoy EC, Black C, Fleischmajer R, Jablonska S, Krieg T, Medsger TA Jr, et al. Scleroderma (systemic sclerosis): classification, subsets and pathogenesis. J Rheumatol 1988;15:202-5.

2. LeRoy EC, Medsger TA Jr. Criteria for the classification of early systemic sclerosis. J Rheumatol 2001;28:1573-6.

3. Giordano M, Valentini G, Migliaresi S, Picillo U, Vatti M. Different antibody patterns and different prognoses in patients with scleroderma with various extent of skin sclerosis. J Rheumatol 1986;13:911-6. 